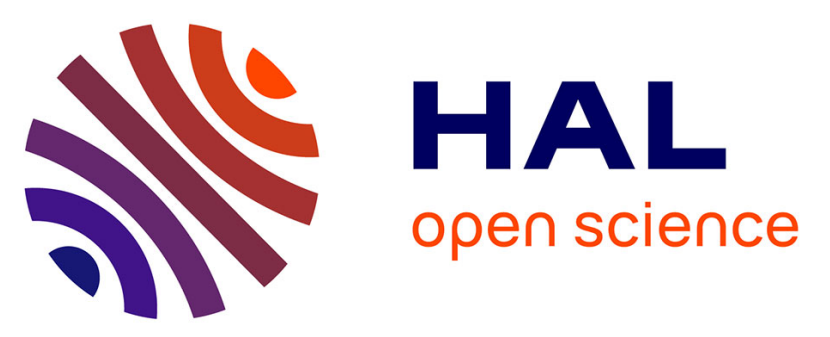

\title{
Windscreen wiper fluid without added screenwash in motor vehicles: a newly identified risk factor for Legionnaires' disease
}

Anders Wallensten, Isabel Oliver, Katherine Ricketts, George Kafatos, James M. Stuart, Carol Joseph

\section{To cite this version:}

Anders Wallensten, Isabel Oliver, Katherine Ricketts, George Kafatos, James M. Stuart, et al.. Windscreen wiper fluid without added screenwash in motor vehicles: a newly identified risk factor for Legionnaires' disease. European Journal of Epidemiology, 2010, 25 (9), pp.661-665. 10.1007/s10654010-9471-3 . hal-00598958

\section{HAL Id: hal-00598958 https://hal.science/hal-00598958}

Submitted on 8 Jun 2011

HAL is a multi-disciplinary open access archive for the deposit and dissemination of scientific research documents, whether they are published or not. The documents may come from teaching and research institutions in France or abroad, or from public or private research centers.
L'archive ouverte pluridisciplinaire HAL, est destinée au dépôt et à la diffusion de documents scientifiques de niveau recherche, publiés ou non, émanant des établissements d'enseignement et de recherche français ou étrangers, des laboratoires publics ou privés. 


\section{Windscreen wiper fluid without added screenwash in motor vehicles: a newly identified risk factor for Legionnaires' disease}

\section{Authors}

Anders Wallensten ${ }^{1,2}$, Isabel Oliver ${ }^{1,3}$, Katherine Ricketts ${ }^{4}$, George Kafatos ${ }^{5}$, James M. Stuart ${ }^{3}$, Carol Joseph ${ }^{4}$

\section{Affiliations}

${ }^{1}$ Health Protection Agency, South West, Stonehouse, GL10 3RF, United Kingdom, ${ }^{2}$ European Programme for Intervention Epidemiology Training (EPIET), European Centre for Disease Prevention and Control (ECDC), Stockholm, Sweden, ${ }^{3}$ Department of Social Medicine, Bristol University, Bristol, BS8 2PS, United Kingdom, ${ }^{4}$ Health Protection Agency, Centre for Infections, Respiratory and Systemic Infections Department, London, NW9 5EQ, United Kingdom, ${ }^{5}$ Health Protection Agency, Centre for Infections, Statistics, Modelling and Bioinformatics Department London, NW9 5EQ, United Kingdom

\section{Correspondance to:}

Dr Anders Wallensten, Smittskyddsinstitutet - Swedish Institute for Infectious Disease Control, Department of Epidemiology, SE-171 82 Solna, Sweden anders.wallensten@smi.se tel. +46 84572364 fax +46 8300626 


\section{Abstract}

A source of infection is rarely identified for sporadic cases of Legionnaires' disease. We found that professional drivers are five times more commonly represented among community acquired sporadic cases in England and Wales than expected. We therefore investigated possible risk exposures in relation to driving or spending time in a motor vehicle. A case control study including all surviving community acquired sporadic cases in England and Wales with onset between 12 July 2008 and 5 March 2009 was carried out. Cases were contacted by phone and controls were consecutively recruited by sequential digital dialling matched by area code, sex and age group. Those who consented were sent a questionnaire asking questions on driving habits, potential sources in vehicles and known risk factors. The results were analysed using logistic regression. 75 cases and 67 controls were included in the study. Multivariable analysis identified two exposures linked to vehicle use associated with an increased risk of Legionnaires' disease: Driving through industrial areas (OR $7 \cdot 2,95 \% \mathrm{Cl} 1 \cdot 5-33 \cdot 7)$ and driving or being a passenger in a vehicle with windscreen wiper fluid not containing added screenwash (OR 47.2, 95\% Cl 3.7-603.6). Not adding screenwash to windscreen wiper fluid is a previously unidentified risk factor and appears to be strongly associated with community acquired sporadic cases of Legionnaires' disease. We estimated that around $20 \%$ of community acquired sporadic cases could be attributed to this exposure. A simple recommendation to use screenwash may mitigate transmission of Legionella bacteria to drivers and passengers. 
Key words: Legionnaires' disease; Legionella; Legionellosis; Driving; Motor vehicles;

Transmission 


\section{Introduction}

Legionnaires' disease is caused by inhalation of subspecies of the bacteria Legionella, which grow in aquatic environments. The incubation period is usually $2-10$ days [1] and the case fatality can be as high as 15\% [2]. Males, the elderly, smokers, the immunosuppressed, and people with chronic disease are at higher risk [2-3]. Outbreaks of Legionnaires' disease are well documented, the source commonly being traced to water aerosol systems such as air conditioning units, cooling towers, showers, fountains, and whirlpools [1]. Sporadic cases are not infrequent, and can represent more than half the annual number of cases in England and Wales [4]. Identified risk factors include overnight stays in a hotel, or other accommodation site [5-6], and exposure to industrial aerosols [7], however a source is rarely identified.

Following the report of an unusually high number of cases of Legionnaires' disease in England and Wales during the summer of 2006 [8], a study was undertaken to identify high risk groups. The occupation of sporadic cases with onset between 2001 and 2006 was compared to data from the Office for National Statistics on the UK workforce [9]. A total of 145 cases were reported among 851,000 professional drivers (including heavy goods vehicle, van, bus and taxi drivers), while 782 cases were reported among $27,061,000$ persons with other occupations. This suggests that professional drivers were at increased risk of Legionnaires' disease ( $R R=5.90$, 95\%Cl: 5.04-6.90 p<0.0001). Previous research also suggests that drivers may be at higher risk. A recent Dutch study found that professional drivers had a three times increased risk [5] and a Turkish serological study identified a higher risk for long distance bus drivers [10]. In addition, a case report from the USA reported the 
isolation of Legionella bacteria in the case's car which had a malfunctioning air conditioning unit [11].

We conducted a case control study to corroborate this finding and to examine whether specific vehicle-related exposures were associated with an increased risk of Legionnaires' disease.

\section{Methods}

Case definition: Sporadic community acquired cases of Legionnaires' disease in residents of England and Wales aged 19-69 years, reported through the national enhanced surveillance scheme and with onset of disease between 15 July 2008 and 9 March 2009. Cases that had travelled abroad in the 2-10 days before onset of illness, those with a suspected nosocomial transmission link and those that were part of an outbreak were excluded. Cases that had died or were unable to give informed consent were also excluded.

We attempted to recruit three controls per case, matched on sex, age group (19-49y or 50-69y), and area of residence. In the analysis these were also classified by season (cold weather Oct-Mar and warm weather Apr-Sep). Controls were excluded if they had travelled abroad in the 2-10 days before completion of the questionnaire and if they had been hospitalised in the two weeks before completion of the questionnaire.

Cases were contacted by telephone and asked if they wished to participate. Controls were consecutively recruited through sequential digit dialling using the case's 
telephone area code to link to the same geographic area. Calls were made in the evenings or at weekends. Cases and controls who consented to participate by telephone were sent a questionnaire, information about the study and a pre- paid return envelope. A reminder was sent after three weeks if they had not responded.

\section{Questionnaire content}

The questionnaire included questions on exposures related to driving or being a passenger in a car or other vehicle, distance and time travelled in a vehicle, time driven with windows open, time driven in rural, urban and industrial areas, and plausible risk exposures in vehicles, such as air conditioning and air re-circulation use. The questions related to average use or average exposure in the two weeks before onset of illness in cases and in the two weeks before completing the questionnaire for controls. Information was also collected on the vehicle type, make, age, service history, content of wind screen wiper fluid reservoir, and whether driving was work or socially related, or both. In addition, questions on the known risk factors for Legionella infections such as smoking, underlying illness, and the use of showers were included.

\section{Data manipulation and statistical analysis}

Data verification, data manipulation and data analysis were carried out using Stata 10.1 (StatCorp, Texas, USA). Initially, risk factors were grouped to create summary variables and single variable analysis was carried out. Any variables with $p<0.1$ were included in a multivariable model. The least significant factors were dropped from the model in a stepwise fashion until all the remaining exposures exhibited a significant association of $p<0.05$. Personal information variables such as sex, age, season, and 
smoking were not part of the stepwise process and were included in the multivariable model at all times. Interactions were tested at a stricter criterion of $p<0.01$.

\section{Ethics approval}

Ethics approval was granted for the study through the Oxford Research Ethics Committee B. Reference number 08/H0605/75. Informed content was obtained from all study participants.

\section{Results}

Case recruitment: During the study period 123 sporadic cases were reported. Ten of these did not have contact details and a further six were not contacted due to staff limitations. Fourteen were excluded according to the specified criteria. The remaining 93 cases agreed to be sent questionnaires, 75 of whom responded (80.6\%); 62 men and 13 women. Nineteen cases were aged under 50 years, 56 were aged $50-69$ years.

Control recruitment: Telephone contact was established with 672 people who were asked to participate as controls; 388 did not fulfil the inclusion criteria. Of the 284 people eligible for inclusion as controls, 117 agreed to be sent a questionnaire (41.2\%). Two questionnaires were not sent due to administrative reasons. Of the remaining 115,70 controls responded (60.9\%), giving a final response rate of $70 / 284$ (24.6\%). Three of those who returned questionnaires did not meet the inclusion criteria, leaving 67 controls in the study, 63 men and 4 women. Twelve controls were aged less than 50 years, 55 were aged 50-69 years. Fifteen cases were matched 
with one control, 17 with two controls and six with three controls. 38 cases were not matched to any control.

\section{Analysis}

The case and control recruitment thus identified a total of 142 individuals that were entered in the analysis. Several exposures linked to driving or being in a vehicle were associated with illness at the $p<0.1$ level in the single variable analysis (Table 1 ). Those with higher odds ratios (>2) were; driving / being a passenger in a van, driving through industrial areas, number of hours as well as ever driving with the window open, hours in vehicle as part of job, vehicle year of manufacture older than 2000 , lack of screenwash (pre-diluted or concentrated screenwash) in windscreen wiper fluid, and not taking showers at home. Those which suggested a protective effect $(\mathrm{OR}<0.5)$ were use of car, bus, train and underground as well as air conditioning in the vehicle especially when at a warm temperature.

In multivariable analysis, after adjusting for sex, age, season and smoking, "driving through industrial area" (OR=7.17; 95\% Cl: 1.52-33.73) and "using no screenwash in the windscreen fluid" (OR=47.24; 95\% Cl: 3.70-603.63) were associated with illness (Table 2). "Shower at home", "driving a van", and "year of make" were of borderline statistical significance but dropped out of the model.

The population attributable risk for driving or being a passenger in a car that did not use screenwash in the windscreen wiper fluid among community acquired sporadic cases aged under 70 years was calculated as $21.8 \% ; 95 \% \mathrm{Cl}(21.0-22.5 \%)$. The 
calculation was carried out using the odds ratio as an approximation to the relative risk assuming $30 \%(15 / 49)$ of the cases were exposed [12].

\section{Discussion}

We found evidence in the surveillance data for England and Wales that professional drivers may be at increased risk of acquiring Legionnaires' disease. Our case control study identified two previously unrecognised potential risk factors that may explain this increased risk among professional drivers and also a proportion of the sporadic cases among non professional drivers who spend time in vehicles. The strength of these associations was high; the relative risk from not using screenwash in the windscreen wiper fluid was nearly 50 . The increased risk of driving through industrial areas is more likely to explain cases in professional drivers and may be linked to a greater exposure to outside sources of Legionella, for example from cooling towers. The finding that not adding screenwash to the water used as windscreen wiper fluid poses a risk is biologically plausible; it is likely that Legionella bacteria would grow in the stagnant water of the windscreen wiper fluid reservoir, which is intermittently sprayed onto the windscreen, creating an aerosol. Some of the aerosol may be sucked into the passenger compartment through the ventilation intake. It is also plausible that screenwashes, as they usually contain biocidal agents like propranolol, inhibit the growth of Legionella. Although we restricted this study to those under 70 years, it is also likely that risk linked to not using screenwash would also apply to older age groups who are at higher risk of Legionnaires' disease.

In addition to the above findings, the single variable analysis also identified driving with the windows down, driving long hours for work and driving a van as associated 
with illness. These may all have been linked to the risk of driving through industrial areas. Also associated with an increased risk were driving an older vehicle and not using showers at home. The single variable analysis found some associations that appeared to be protective: travelling by car, bus and train and using a vehicle with air conditioning. None of these factors retained their significance in the multivariable model.

Ultimately, recruiting three controls per case as planned was not possible with the resources and time available as the selected method of control recruitment turned out to be very resource intensive. Due to the number of cases $(n=38)$ without any matched controls, applying matched analysis techniques using conditional logistic regression was no longer ideal. We therefore did an unmatched analysis using logistic regression that included adjustment for the matching variables of age and sex. Adjustment for area of residence was not possible due to the low numbers of cases and controls in the same local area. Unmatched analysis of a matched study may well introduce some selection bias but this is likely to underestimate the true strength of association [13].

These findings offer a possible explanation for the higher risk among professional drivers identified in the Netherlands [5]. During the course of our study, a Japanese study was published [14] whose results were in line with our findings and those from the Netherlands. The Japanese study showed a disproportionately high number of cases among transportation industry workers. They also identified evidence of Legionella bacteria in air conditioning evaporators of discarded cars suggesting that air conditioning units may be a source of infection. We did not find evidence of this in our 
multivariable analysis and our single variable analysis actually found a lower risk for those using cars with air conditioning systems. In a second paper the same research group hypothesised that contaminated aerosols may enter the car when a car drives through puddles as they managed to isolate Legionella bacteria from rain puddles on roads [15].

Of the identified risk exposures, the risk found to be associated with not using screenwash in the windscreen wiper fluid was the most intriguing. This exposure pathway needs further investigation. In a pilot study carried out by the UK Health Protection Agency, the windscreen wiper fluid was tested in a sample of cars with and without added screenwash. Legionella bacteria were isolated from the windscreen wiper fluid of one car out of five that did not use screenwash while none were identified from 16 cars that did use screenwash (unpublished data). We estimate that around $20 \%$ of community acquired sporadic cases under the age of 70 years in England and Wales could be prevented by using screenwash. This simple public health advice may be of worldwide relevance in reducing morbidity and mortality from Legionnaires' disease.

\section{Acknowledgements}

The study was funded entirely by the Health Protection Agency. We would like to thank all staff at the Health Protection Agency who assisted in the investigation, in particular: Rebecca Close, Magdalene Mbanefo, Esam Gharish, Falguni Naik, and Anitra Jones. We would also like to thank Nick Phin for his support of the study, and John $V$ Lee and Sandra Lai for carrying out the pilot study into the sampling of windscreen wiper fluid. 


\section{References}

1. American Public Health Association. Control of communicable diseases manual. In: Heymann DL, editor. 18th edition ed. Baltimore, Md: United Book Press, Inc; 2004. p. 294.

2. Diederen BM. Legionella spp. and Legionnaires' disease. J Infect. 2008 Jan;56(1):1-12.

3. Marston BJ, Lipman HB, Breiman RF. Surveillance for Legionnaires' disease. Risk factors for morbidity and mortality. Arch Intern Med. 1994 Nov 14;154(21):2417-22. 4. Health Protection Agency. Epidemiological data on Legionnaires' disease, legionnaires' disease in residents of England and Wales - nosocomial, travel or community acquired cases, 1980 - 2008. Available at:

http://www.hpa.org.uk/web/HPAweb\&HPAwebStandard/HPAweb_C/1195733748327. Accessed 12/08/2009.

5. Den Boer JW, Nijhof J, Friesema I. Risk factors for sporadic communityacquired Legionnaires' disease. A 3-year national case-control study. Public Health. 2006 Jun;120(6):566-71.

6. Che D, Campese C, Santa-Olalla P, Jacquier G, Bitar D, Bernillon P, et al. Sporadic community-acquired Legionnaires' disease in France: a 2-year national matched case-control study. Epidemiol Infect. 2008 Dec;136(12):1684-90.

7. Che D, Decludt B, Campese C, Desenclos JC. Sporadic cases of community acquired legionnaires' disease: an ecological study to identify new sources of contamination. J Epidemiol Community Health. 2003 Jun;57(6):466-9. 
8. Health Protection Agency. National increase in cases of legionnaires' disease. 2006 Available at: http://www.hpa.org.uk/cdr/archives/archive06/News/news3706.htm. Accessed 22/10/2009.

9. National Statistics Online. ONS - Labour Force Survey April to June 2007. Available at: http://www.statistics.gov.uk/STATBASE/Product.asp?vlnk=14248. Accessed 12/8/2009.

10. Polat Y, Ergin C, Kaleli I, Pinar A. [Investigation of Legionella pneumophila seropositivity in the professional long distance drivers as a risky occupation]. Mikrobiyol Bul. 2007 Apr;41(2):211-7.

11. Pinar A, Ramirez JA, Schindler LL, Miller RD, Summersgill JT. The use of heteroduplex analysis of polymerase chain reaction products to support the possible transmission of Legionella pneumophila from a malfunctioning automobile air conditioner. Infect Control Hosp Epidemiol. 2002 Mar;23(3):145-7.

12. Armitage P, Berry G. Attributable risk. Statistical methods in medical research. Third edition ed. Oxford: Blackwell Publishers; 1994. p. 519-22.

13. Rothman KJ, Greenland S, Lash TL. Design strategies to improve study accuracy. Modern Epidemiology. 3rd ed. Philadelphia: Lippincott, Williams and Wilkins; 2008. p. $168-82$.

14. Sakamoto R, Ohno A, Nakahara T, Satomura K, Iwanaga S, Kouyama Y, et al. Is driving a car a risk for Legionnaires' disease? Epidemiol Infect. 2009 Nov;137(11):161522.

15. Sakamoto R, Ohno A, Nakahara T, Satomura K, Iwanaga S, Kouyama Y, et al. Legionella pneumophila in rainwater on roads. Emerg Infect Dis. 2009 Aug;15(8):1295-7. 


\section{Table 1}

Risk factors for sporadic cases of Legionnaires' disease; single variable analysis $(p<0.1)$

1a. Exposures relating to time spent in vehicle as a driver/passenger

Exposure

\begin{tabular}{ccccccccc} 
(n. available for analysis) & & Cases & $\%$ & Controls & $\%$ & OR & 95\% Cl & P-value \\
\hline Use of car & No & 14 & & 3 & & 1.00 & baseline \\
$(130)$ & Yes & 54 & 79.4 & 59 & 95.2 & 0.20 & $(0.05,0.72)$ & 0.006 \\
Use of van & No & 49 & & 57 & & 1.00 & baseline & 0.003 \\
$(130)$ & Yes & 19 & 27.9 & 5 & 8.1 & 4.42 & $(1.54,12.71)$ & baseline \\
Use of bus & No & 61 & & 48 & & 1.00 & 0.031 \\
(129) & Yes & 6 & 9.0 & 14 & 22.6 & 0.34 & $(0.12,0.94)$ & 0.034
\end{tabular}

Driving through industrial

$\begin{array}{lllllllll}\text { areas } & \text { No } & 44 & & 51 & & 1.00 & \text { baseline } \\ (142) & \text { Yes } & 31 & 41.3 & 16 & 23.9 & 2.25 & (1.09,4.64) & 0.026\end{array}$

Daily hours with window

$\begin{array}{lcccccccc}\text { open } & \text { Never } & 4 & 5.9 & 17 & 27.4 & 1.00 & \text { baseline } & \\ (130) & <2 & 36 & 53.0 & 39 & 62.9 & 3.92 & (1.21,12.76) & \\ & >=2 & 28 & 41.2 & 6 & 9.7 & 19.83 & (4.88,80.54) & <0.001\end{array}$

$\begin{array}{ccccccccc}\text { Ever having window open } & \text { No } & 4 & & 17 & & 1.00 & \text { baseline } \\ (130) & \text { Yes } & 64 & 94.1 & 45 & 72.6 & 6.04 & (1.91,19.17) & 0.001 \\ & & & & & & & & \\ \text { Driving as part of job } & \text { No } & 38 & & 43 & & 1.00 & \text { baseline } \\ (131) & \text { Yes } & 31 & 44.9 & 19 & 30.6 & 1.85 & (0.90,3.79) & 0.092\end{array}$




\begin{tabular}{|c|c|c|c|c|c|c|c|c|}
\hline Daily hours in vehicle & $<2$ & 3 & 9.7 & 9 & 47.4 & 1.00 & baseline & \\
\hline for job & $2-4$ & 11 & 35.5 & 6 & 31.6 & 5.50 & $(1.06,28.42)$ & \\
\hline \multirow[t]{2}{*}{$(50)$} & $4-6$ & 7 & 22.6 & 2 & 10.5 & 10.50 & $(1.36,81.05)$ & \\
\hline & $>8$ & 10 & 32.3 & 2 & 10.5 & 15.00 & $(2.02,111.17)$ & 0.015 \\
\hline
\end{tabular}

\section{1b. Exposures relating to vehicle}

\section{Exposure}

\begin{tabular}{ccccccccc} 
(n. available for analysis) & & Cases & $\%$ & Controls & $\%$ & OR & 95\% Cl & P-value \\
\hline Year of manufacture & $2004-2009$ & 14 & 26.4 & 24 & 43.6 & 1.00 & baseline \\
$(108)$ & $2000-2004$ & 18 & 34.0 & 20 & 36.4 & 1.54 & $(0.62,3.86)$ \\
& $<2000$ & 21 & 39.6 & 11 & 20.0 & 3.27 & $(1.22,8.75)$ & 0.052 \\
Air conditioning in vehicle & No & 31 & & 16 & & 1.00 & baseline \\
$(122)$ & Yes & 32 & 50.8 & 43 & 72.9 & 0.38 & $(0.18,0.82)$ & 0.012
\end{tabular}

Air conditioning

temperature

(54)

$\begin{array}{lrrrrrrr}\text { Cold } & 7 & 41.2 & 5 & 13.5 & 1.00 & \text { baseline } & \\ \text { Neutral } & 8 & 47.1 & 22 & 59.5 & 0.26 & (0.06,1.06) & \\ \text { Warm } & 2 & 11.8 & 10 & 27.0 & 0.14 & (0.02,0.96) & 0.068\end{array}$

Use of screenwash

(concentrate or prediluted)

in windscreen wiper fluid*

(100)

Yes $\quad 34$

50

1.00 baseline

No

$15 \quad 30.6$

1

$2.0 \quad 22.06$

$(2.78,174.92)<0.001$

1c. Exposures relating to other activities

\section{Exposure}

(n. available for analysis)
Cases \% Controls \%

OR

$95 \% \mathrm{Cl}$

P-

Use of train

No

64

47

1.00

baseline 


\begin{tabular}{|c|c|c|c|c|c|c|c|c|}
\hline$(136)$ & Yes & 7 & 9.9 & 18 & 27.7 & 0.29 & $(0.11,0.74)$ & 0.007 \\
\hline Use of underground & No & 65 & & 53 & & 1.00 & baseline & \\
\hline$(136)$ & Yes & 6 & 8.5 & 12 & 18.5 & 0.41 & $(0.14,1.16)$ & 0.083 \\
\hline \multicolumn{9}{|l|}{ Showers taken at } \\
\hline home & Daily & 27 & 36.0 & 43 & 66.2 & 1.00 & baseline & \\
\hline \multirow[t]{4}{*}{$(140)$} & 5-6 times & 7 & 9.3 & 7 & 10.8 & 1.59 & $(0.50,5.04)$ & \\
\hline & 3-4 times & 12 & 16.0 & 6 & 9.2 & 3.19 & $(1.07,9.49)$ & \\
\hline & $1-2$ times & 5 & 6.7 & 3 & 4.6 & 2.65 & $(0.59,12.02)$ & \\
\hline & None & 24 & 32.0 & 6 & 9.2 & 6.37 & $(2.31,17.59)$ & 0.002 \\
\hline Smoking & No & 6 & & 33 & & 1.00 & baseline & \\
\hline$(140)$ & Yes & 69 & 92.0 & 32 & 49.2 & 11.86 & $(4.52,31.15)$ & $<0.001$ \\
\hline
\end{tabular}

Table 2

Vehicle related risk factors for Legionnaires' disease: multivariable analysis

\begin{tabular}{ccccc} 
Exposure & & OR $^{\star}$ & 95\% Cl & p-value \\
\hline Driving through industrial area & No & 1.00 & baseline & \\
& Yes & 7.17 & $(1.52,33.73)$ & 0.007
\end{tabular}

\begin{tabular}{|c|c|c|c|c|}
\hline \multirow[t]{2}{*}{ windscreen wiper fluid } & Yes & 1.00 & baseline & \\
\hline & No & 47.24 & $(3.70,603.63)$ & $<0.001$ \\
\hline
\end{tabular}

